This is a self-archived - parallel published version of this article in the publication archive of the University of Vaasa. It might differ from the original.

\title{
The transport service triad : a key unit of analysis
}

Author(s): Andersson, Dan; Dubois, Anna; Eriksson, Victor; Hulthén, Kajsa; Holma, Anne-Maria

Title: $\quad$ The transport service triad : a key unit of analysis

Year: $\quad 2019$

Version: Accepted manuscript

Copyright (C) Emerald Publishing

Please cite the original version:

Andersson, D., Dubois, A., Eriksson, V., Hulthén, K., \& Holma, A-M., (2019). The transport service triad : a key unit of analysis. Journal of Business and Industrial Marketing 34(1), 253-266. https://doi.org/10.1108/JBIM-10-2018-0299 


\title{
The transport service triad: a key unit of analysis
}

\author{
Dan Andersson, Anna Dubois, Victor Eriksson, Kajsa Hulthen, \\ Chalmers University of Technology, Gothenburg, Sweden \\ Anne-Maria Holma \\ University of Vaasa, Vaasa, Finland
}

\begin{abstract}
Purpose -

The purpose of the paper is to identify and discuss the transport service triad (TST) as a key unit of analysis to understand the operations and conditions for change in freight transport systems at the micro level, i.e. at the level of analysis where business decisions and change interaction take place.

Design/methodology/approach -

The theoretical framing is rooted in the IMP approach and in the literature on triads. A case study approach is

used to illustrate the TST by analyzing a case involving a wholesaler of installation products, tools and supplies, a main construction company and a transport service provider.

Findings - The paper shows how the connections between the business relationships in the TST, influenced by connections to relationships outside the triad, impact on the efficiency in freight transport. The paper illustrates hoW analysis of TSTS can be applied in micro-level studies of change in freight transport systems and in supply networks.

Research limitations/implications - The triadic approach is instrumental to understand change in the transport system because it includes all relevant parties and relationships of concern, as well as the logic framing of their actions. However, while arguing that TSTS are generic to their nature, each TST is unique and needs to be identified and analyzed in its specific context.

Practical implications - The suggested framework may contribute to an understanding of the embeddedness of transport services in supply/ business networks. The framework may support the development of new ways of operating and creating value for customers and offering sustainable transport solutions.

Originality/value - From the transport policy makers' perspective, micro-level analysis is important to understand behavioral adjustments to new policies.
\end{abstract}

Keywords Transport, Supply chain, Relationship, Networks, Triad, Freight

Paper type Research paper

\section{Introduction}

The transport system will be subject to massive change in the coming decades. Especially, its climate impact calls for various developments (European Commission, 2016). In the EU, the goal is to reduce carbon emissions from transport by 60 per cent as of 2050 (European Commission, 2011), and in Sweden to make a 70 per cent reduction from 2010 to 2030 (Swedish Government, 2017). To achieve this, the focus has mostly been on the development of infrastructure, vehicle technologies and alternative fuels (Johansson, 2013). However, Banister et al. (2000: 27) argue that:

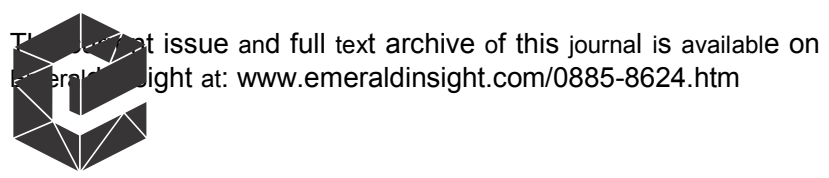

Journal of Business \& Industrial Marketing

(c) Emerald Publishing Limited [ISSN 0885-8624]

[DOI 10.1108/JBIM-10-2018-0299]
"Improvements in vehicle technology alone will not achieve the targets. More fundamental changes have to take place in the way in which people make travel choices and in the means by which freight is transported."

In this paper, we focus on the latter, i.e. freight transport. In this business context, transport activities are embedded in broader logistics setups, and because of the environmental impact of transport, many logistics service providers have set ambitious targets to reduce their emissions (McKinnon and Piecyk, 2012). However, buyers of transport services may hamper the "greening" of transport service providers because some of the vital decisions, regarding e.g. lead time, frequency and delivery time windows, are included in business agreements between buyers and providers of transport services in a standardized manner (Lammgård, 2007; Isaksson, 2012; Rogerson, 2016). Moreover, the development of new types of transport solutions is complicated by the fact that all transport activities are 
embedded in complex supply chains and networks, and thus the impact of new solutions on the transport system is very difficult to predict and simulate. The embedded nature of transport activities entails interdependencies that require interaction among the actors involved as buyers and suppliers of both goods and transport services. Therefore, it is vital to understand the relationships between the key actors, and how these relationships are connected, to analyze change in the system.

The paper focuses on freight transport services and their embeddedness in supply networks. We take the starting point, in that the exchange of transport services is depending on the exchange of goods, because every exchange of goods between any two firms generates a demand for transport service. Hence, a triad, henceforth referred to as the transport service triad (TST), consisting of the buyer and supplier of the goods and the supplier of the transport service, makes up a core unit of analysis as part of a wider supply network of actors and relationships. TSTs have been addressed (without using the term) in previous research on transport services and (connected) business relationships (Andersson et al., 2014). For instance, Gentry (1996), in her study of the role of carriers in buyer-supplier relationships, concluded that the earlier the transport service providers become involved in the strategic planning process with buyers and suppliers (of goods), the better opportunities to fully exploit the potential benefits of the relationships. Moreover, Carter and Ferrin (1995) investigated the effect of trilateral collaboration on transport costs for the buyer and supplier of goods and the transport service provider. The study shows that transport cost was reduced as a result from triadic collaboration. In a study reported by Rodrigues et al. (2010), management of the demand for transport services in a holistic and collaborative way was found to reduce the risk for low capacity utilization. In the logistics context, Beier (1989) argues that the triad should constitute the "minimum unit of analysis for logistics research", because the logistics service provider, having a different perspective on the transactions, occupies a potent position in a logistics triad and may be able to identify and pass on information that may lead to more efficient transaction processing. Moreover, Tanskanen et al. (2015) studied logistics innovation from a triadic perspective. Also, Bask (2001) suggests that a triadic approach is most appropriate when matching logistics services to seller-buyer relationships in supply chains. However, according to Selviaridis and Spring (2007), existing studies of logistics triads do not provide "supra-dyadic" insights, i.e. insights that cannot be captured by dyadic approaches. For example, they claim that these studies do not focus on the indirect relationships, and thus not on the mediating roles that are essential in third-party logistics. The logistics service provider fulfils part of, or all, the logistical needs in the exchange between the buyer and supplier, and therefore, a triadic approach could explicitly capture the indirect links in the supply network and the mediating role of a logistics service provider (2007). The TST includes an indirect link between the transport service provider and buyer (of goods), or alternatively between the transport service provider and supplier (of goods). Hence, the TST provides a unit of analysis for understanding this important indirect link and the embeddedness of transport services in supply networks. Figure 1 illustrates the TST in a situation where the supplier of goods buys the transport service and incorporates it into its offering. However, transport services can also be bought by the firm buying the goods.

The aim of this paper is to identify and discuss the TST as a key unit of analysis to better understand change in freight transport systems and supply networks at the micro level, i.e. at the level of analysis where business decisions and interaction take place.

The nature of the relationships between buyers and providers of transport services has been subject to previous research. For instance, Andersson and Norrman (2002) suggest that transport service providers need to be more involved in the definition of resources, processes and intangible output. Networking aspects have also been addressed, e.g. by Hertz and Macquet (2006) pointing at how firms in logistics networks rely on networking because their business idea is based on connecting organizations, coordinating activities and combining resources. However, Holter et al. (2008) argue that there are few studies focusing on the purchasing process for transport services, and that most studies have focused on logistics services rather than on transport services per se. Three literature reviews related to purchasing of transport services confirm the lack of focus on transport. These reviews conclude that the focus instead has been set on; third-party logistics development process (Marasco, 2008); carrier-selection decision process (Meixel and Norbis, 2008); and frameworks for purchasing logistics services (selviaridis and Spring, 2007).

The paper is outlined as follows. In the next section, we present the frame of reference, including the theoretical background. In Section 3, the method is described, followed by a case description and analysis in Section 4 . Section 5 contains a concluding discussion in which we discuss how TST analysis can contribute to a better understanding of change in and of the transport system, as well as suggestions for further research.

\section{Frame of reference}

\subsection{Theoretical background}

The focus in business research has moved from a firm or dyadic focus on single buyer-seller relationships, toward capturing dynamics in wider networks of connected relationships (Anderson et al., 1994; Håkansson and Snehota, 2006; Ritter and Gemünden, 2003). Owing to the complexity and the lack of boundaries in networks, it has been argued that "data reduction" is necessary to enable network analysis (Smith and

Figure 1 The TS

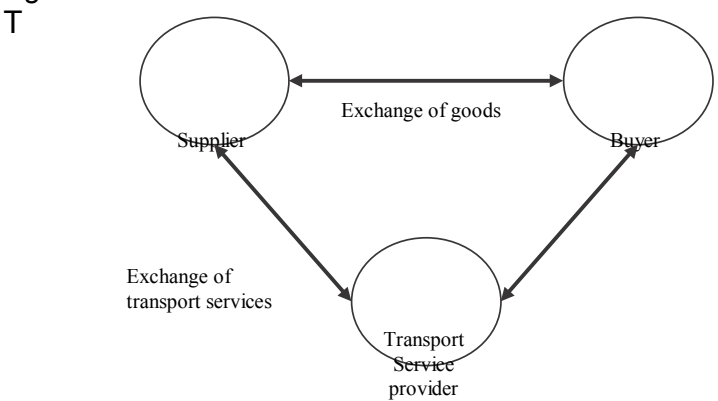


Laage-Hellman, 1992). Therefore, with connectedness as a central feature of business relationships, triads have been suggested as the smallest conceivable unit of analysis wherein connectedness can be investigated (Laage-Hellman, 1989; Halinen and Törnroos, 1998; Havila, 1996; Ritter, 2000). A three-actor constellation forms a triad if the three relationships in the triad are connected, either directly or indirectly, and the three actors are associated (Vedel et al., 2016).

The roots of triad research can be found in sociology and in the works of Simmel (1908). However, the interest to study triads in business contexts has increased lately, resulting in a number of conceptual (Sengupta et al., 2018b; Siltaloppi and Vargo, 2017; Vedel et al., 2016), as well as empirical studies (Broekhuis and Scholten, 2018; Holma et al., 2015; KaratZas et al., 2016; Sengupta et al., 2018a) where triads are in focus.

Triadic studies can be divided into studies of triadic contexts and triadic structures, depending on the unit of analysis. In studies on triadic contexts, the unit(s) of analysis has been one or two of the actors (firms) of the triad(s) (Van der Valk and van Iwaarden, 2011; van Iwaarden and van der Valk, 2013). In studies of triadic structures, three (directly or indirectly) connected actors are investigated (Choi and Wu, 2009; Finne and Holmström, 2013). Industrial network analysis focusing on the substance (resource ties, activity links and actor bonds) and function (for individual firms, the relationships between them and for third parties of relationships (i.e. connected relationships), as suggested by Håkansson and Snehota (1995) is also well suited for analysis of triads.

\subsection{Triadic structures and types of triads}

Vedel et al. (2016) divide triadic structures into four types, depending on the degree of the triad's internal cohesiveness and the ability of the triad to act as an entity. In a group-like triad (Dubois and Fredriksson, 2008; Holma, 2012; Holma et al., 2015), the degree of internal cohesiveness can be high, and there are strong ties and direct connections between all the three actors. In a set-of-connected-actors type of triad, there is low degree of internal cohesiveness, the ties between the actors are weak and all the three actors are not necessarily directly connected. These two types of triads do not act as distinct entities in their dealings outside the triad. In a coalition and hubdriven strategic network type of triad, the actors act as distinct entities, but in different ways. Coalition is featured by a high degree of cohesiveness and direct connections, whereas in a hub-driven strategic network, the members are indirectly connected and have a low degree of cohesiveness. In the latter, the hub firm represents the triad members, and the relationships can be managed separately by the hub firm. However, Vedel et al. (2016) point out that an open triad involving a supplier, buyer and an intermediary can represent a highly specialized relationship. The intermediary can provide specialized and valued services, and there is little incentive for the two disconnected actors to develop direct relationships (2016).

Wynstra et al. (2015: 8) divide service triads into three categories depending on which one of the three actors that initiates the exchange between the other two actors: supplierinitiated, buyer-initiated and customer-initiated service triads. Supplier-initiated service triads have their starting point in a decision by the supplier to use a third party to mediate the exchange with its customer. Buyer-initiated service triads are formed when the buyer sources (or outsources) a service by using a third party. Customer-initiated service triads origin from a decision where the customer uses a third party to mediate and/or support the exchange with a supplier (2015).

\subsection{Roles in triads}

Simmel (1908) distinguishes among the three roles of the third actor: "non-partisan mediator" (solving conflicts between the other two parties), "tertius gaudens" (using its position for gaining advantage of the two parties' mutual strangeness), "divides and rules" (causing actively conflicts between the other two parties). These roles have later been discussed in several studies (Adobor and McMullen, 2014; Burt, 2000; Komulainen et al., 2016; Schreiner, 2015; Vedel, 2016). In their literature review, Siltaloppi and Vargo (2017: 4) identify three analytically distinct forms of triads in existing literature:

1 Brokerage is focused on how the third actor influences, manages or facilitates interaction between two others (Obstfeld et al., 2014). The broker can use its position in three different ways: first, to create relationships between previously disconnected actors to facilitate knowledge creation and innovation, second, to use the information asymmetry between the two parties for its own benefit and third, to distribute information between two parties, whether or not they are connected directly (Obstfeld et al., 2014).

2 Mediation describes different mechanisms by which a dyadic relationship affects and is affected by a relationship with a third actor (Andersson et al., 1994), i.e. the embeddedness of dyads within triads (Krackhardt, 1998). Siltaloppi and Vargo (2017) distinguish the three mechanisms of mediation. Dyadic influence, demonstrating how a third actor can influence behavior in a focal dyad by providing information to one of the two focal actors. Normative commitments refer to a situation in which existing commitments to a third party constitute constraints on activities in a focal relationship. Cognitive dispositions is a mechanism of mediation characterized by the "human tendency to adopt certain forms of activity unconsciously as a result of interactions in a particular context" (Siltaloppi and Vargo, 2017:8).

3 Coalition captures the configuration and evolution of ties in the three-actor system as a whole, describing the process of how actors form and balance relationships in a triad (Siltaloppi and Vargo, 2017). There is a higher probability of actors to form a relationship if they have a relationship with a common third actor (Granovetter, 1973). When this relationship is formed, the third actor acts as an arbitrator, stabilizing and sustaining the relationship over time (Simmel, 1950), leading oftentimes to the development of direct connections between all the three actors (Siltaloppi and Vargo, 2017).

\subsection{Service triads and the transport service triad}

A recent stream of research has introduced the "service triad" concept, which includes features that are relevant to those of the more specific TSTs: the service buyer contracts a supplier to deliver services directly to the service buyer's customer 
(Hartmann and Herb, 2014; van Iwaarden and van der Valk, 2013; Wynstra et al., 2015). The three actors, thus, have specific and predefined roles in the "service triad", i.e. buyer, distributor and user of the services. $\mathrm{Li}$ and Choi (2009) suggest that the lack of understanding of the dynamic nature of triadic relationships is a reason for failed attempts in many service outsourcing situations. In line with this, Sengupta et al. (2018a: 334) call for the application of service triad research particularly in logistics and other industries that otherwise are primarily looked at from a dyadic goods-dominant lens.

Wynstra et al. (2015) argue that triads provide a critical context to better understand the nature and relative importance of various inputs for the service process. Moreover, they suggest that "service triads" are generic triads, including three specific types of actors with different roles. In line with this, we suggest a similar approach to TSTs with the buyer and supplier of the transport service and the goods subject to transport defining the TST. In a TST, there is an indirect connection either between the buyer of the goods and transport service provider or between the supplier of the goods and transport service provider, because the TST builds on two business exchanges: one relating to the goods to be transported and the other to the transport service itself.

In a transport context, each exchange of goods between a buyer and supplier generates a demand for transport services; consequently, either the buyer or supplier initiates the exchange with the transport service provider, and thus connects the transport service provider to the buyer-supplier dyad.

A central concept in triad research is connectedness, which refers to a situation where "exchange between $A$ and $B$ to some extent affects exchange between $B$ and $C$ and vice versa" (Yamagishi et al., 1988: 835). In TSTs, the exchange of goods between the buyer and supplier affects the relationship between the buyer and supplier of transport services. Figure 2 illustrates the two types of TSTs. In both illustrations, all three actors are interconnected. The difference between the two types of triads is the nature of the transport service provider's connection with the buyer of transport services, i.e. if the buyer or supplier of goods is the one buying the transport service. In the type of triad illustrated on the left, the supplier of goods buys the transport service, and is thereby directly connected to (i.e. involved in business exchange with) the transport service provider. In the illustration on the right, the transport service provider is directly connected to the buyer of goods because this actor buys the transport service. Furthermore, each of these actors is also connected, directly and/or indirectly to other actors outside the triad, indicating that the focal triad is

Figure 2 The relationships and the connections involved in a TS

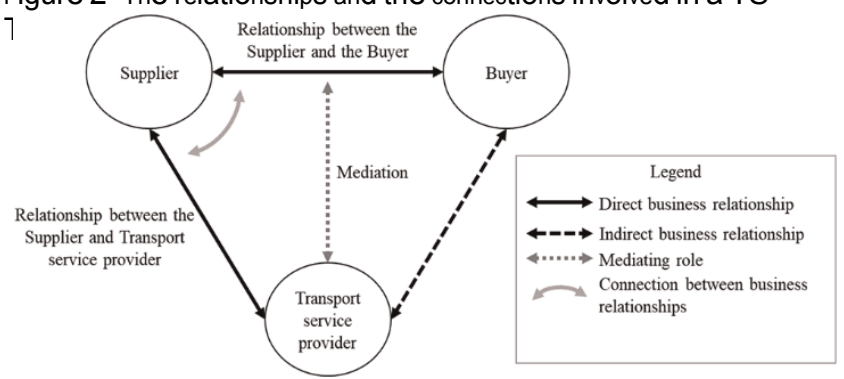

embedded in a wider supply network, which is illustrated by the lines pointing outward from the three focal actors (see Figure 2). An implication of this embeddedness is that each actor is also involved in other TSTs, and that these connections have an impact on the individual TSTs.

Any one of the actors in a triad may take on a mediating role in relation to the other two (Obstfeld, 2005; Obstfeld et al., 2014). Moreover, interaction among the actors in a triad may affect other actors (outside the triad) in different ways, which in turn may lead to changes in the relationships, and their connections, within the triad. There may be different motives for actors to initiate change, e.g. to pool resources (Madhavan et al., 2004). For TSTs, interaction among all three actors has been found to enhance efficient resource utilization and to facilitate quality improvement in the triad (Gentry, 1996), and thus initiation and mediation of interaction both within and beyond the TST are both vital aspects to capture.

Previous research has identified different types of triads in terms of the connections between the relationships in the triads. Taking the service triad as a starting point, we define the concept of a TST as consisting of the buyer and supplier of the goods, the buyer of transport services (either the buyer or supplier of the goods) and the transport service provider. Similar to the notion of the service triad, we consider the TST as a generic type of triad because every exchange of a transport service involves the three types of actor roles forming one of the two types of triads illustrated in Figure 2.

\subsection{Transport service triads embedded in supply networks}

To be able to analyze changes and their consequences, we rely on the industrial network theory (Håkansson and Snehota, 1995; Gadde et al., 2010) with its three main elements, or network layers; actors that perform activities by the use of resources. The connectedness discussed above can be conceptualized in terms of relationship substance. Following Håkansson and Snehota (1995), we use the terms activity links, resource ties and actor bonds. Change in any of these network layers impacts on the connections among the elements through adaptations. To change activity links, resource ties and actor bonds, interaction between actors is needed. When firms interact and learn from each other, the relationship substance develops. Furthermore, connections between relationships may change as a result from such changes.

For TSTs, the actors are defined by their involvement in the exchange of goods and transport services. Depending on the need for interaction to develop and handle the substance in the relationships, development of the actor bonds may be needed. The activities involved in the TST are related to the transport activity. The transport activity and the activities preceding and following the transport activity are sequentially dependent (Dubois et al., 2004), and thus in need of coordination among the firms involved. Such coordination can be handled in different ways and may call for interaction among all three parties involved in the TST. Every transport activity entails a need for specific coordination regarding; what is to be transported, from where to where, at what time to pick up and deliver the goods, etc. Hence, the transport activities are, by definition, an important part of the substance of the relationships in a TST with regard to activity links. The relevant resources involved in a TST are the ones activated by 
the transport activity (e.g. Vehicles, load carriers) and other resources needed to carry out the transport such as cranes, IT systems, terminals, road space, etc. Furthermore, other resources that are affected by the organizing of the transport activities are important to consider. To what degree resource ties develop in the relationships in the TST depends on whether the resources are specifically adapted to a certain counterpart or whether they are standardized and thus possible to use in relation to other counterparts. Resource utilization, i.e. how activities activate resources, is fundamental to achieve efficiency. Efficient resource utilization is enabled by similarity among activities (Richardson, 1972; Dubois, 1998). For transport activities, similarity among activities is needed to enable efficient utilization of, e.g. a truck in a transport activity from point $A$ to point $B$, up to the truck's capacity limits, while to fully utilize the truck as a resource, also complementarity among activities is required, e.g. that the truck can be used to carry loads also from point $B$ to point $A$, etc.

In addition to substance, relationships also have functions; for the individual firms, the relationship itself and for third parties (Håkansson and Snehota, 1995). For the TST, we need to distinguish between the specific functions of the relationships within the triad, and the relationships that each party are involved in with other counterparts, or "fourth parties" in relation to the focal transport activity. Of particular importance for the TST as a unit of analysis is the connections between TSTs, i.e. the three parties' involvement in other TSTs require attention (see Figure 3 below).

Based on the notions presented in this frame of reference, we will use a case as an illustration of a TST to further conceptualize the TST and to discuss the possibilities to utilize the TST as a unit of analysis to further our understanding of change in the transport system and in supply networks. Two research topics generated from the framework call for further scrutiny: the generic features of a TST and the connections between the relationships in a TST and other relationships.

\section{Method}

This paper builds on a qualitative research method and uses a single-case study design, which is well suited for capturing a phenomenon in its context (Flyvbjerg, 2006; Easton, 2010). The phenomenon studied in this paper is the embeddedness of transport activities in supply networks. Furthermore, the casebased research approach allows for the inclusion and combination of multiple sources of evidence. This approach was used because a convincing, deep, and rich case description was deemed necessary so as to capture the phenomenon (Ellram, 1996: Dubois and Araujo, 2007). Furthermore, Easton (1995: 371) points to that "case research is perhaps the most appropriate methodology for research into Industrial Networks".

The case presented in this paper draws mainly on data from a research project about logistics planning aimed at more energyefficient freight transports in Sweden. There are three main actors in the case (made anonymous): the supplier of the goods (henceforth referred to as the Wholesaler), a large main construction company buying the goods (henceforth referred to as the Contractor) and the transport service provider (henceforth referred to as the Hauler). Both the Wholesaler and Contractor are large firms in their respective businesses, and they have a long-lasting relationship with each other. Moreover, the Hauler, which is involved in a business relationship with the Wholesaler, is solely responsible for every transport in a geographic region to the customers of the Wholesaler.

The collection of data was performed in 2016-2017. The case study is based on interviews, participant observations at site visits and secondary sources such as transport data (Excel sheets), annual reports and websites. Interviews have been carried out with all three actors. These interviews have been important to capture diverse perspectives and different business logics from each actor in the case (Eisenhardt and Graebner, 2007). The interviews with the three actors and the sequence of the interviews are presented in Table $I$ and Figure 4, respectively. The sequence in Figure 4 is of importance because one interview inspired the next, and thus, the case description unfolded in an interactive process between the interviewees and the interviewer(s). In addition, each of the three dyads embedded in the triad is analyzed in the context of the other two dyads to which it is connected and from both ends (Halinen and Törnroos, 1998).

Figure 3 The TsT embedded in the supply network

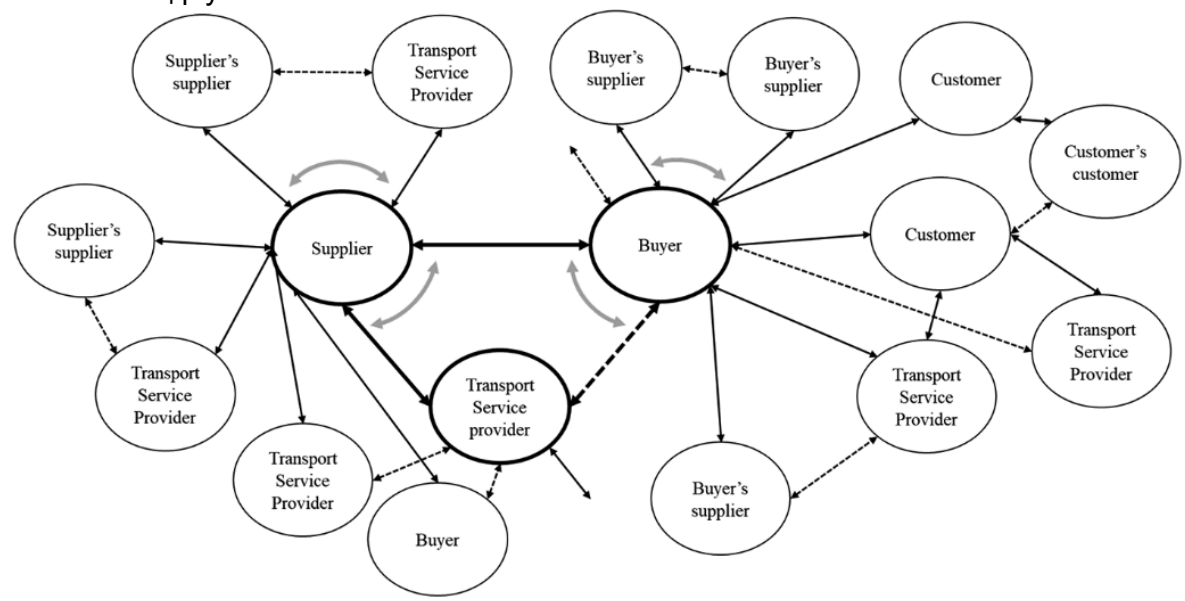


Table I Sources of data

Company and data source Interviewee(s)

Date Duration (in min) The Wholesaler

Interview

Telephone interview

Interview

Interview

Site visit and interview

Interview

The Contractor

Telephone interview

Interview

Interview

Interview

Telephone interview

The Hauler

Site visit and interview Interview
Head of transport

Key account manager

Key account manager

Key account manager

Head of transport, transport developer

Transport developer

Category manager

Category manager

Category manager

Sustainability development leader

Logistics manager
April 29, 2016

January 16, 2017

January 24, 2017

February 28, 2017

April 24, 2017

October 12, 2017

January 16, 2017

January 24, 2017

February 10, 2017

February 28, 2017

March 27, 2017

April 03, 2017

May 24, 2017
180

-30

$\square 90$

90

210

150

-30

$\square 90$

45

90

60

Vice president, transport manager, quality manager, terminal manager Transport manager

Notes: *In conjunction (telephone); **in conjunction

Figure 4 The interviewees and the sequence of interviews

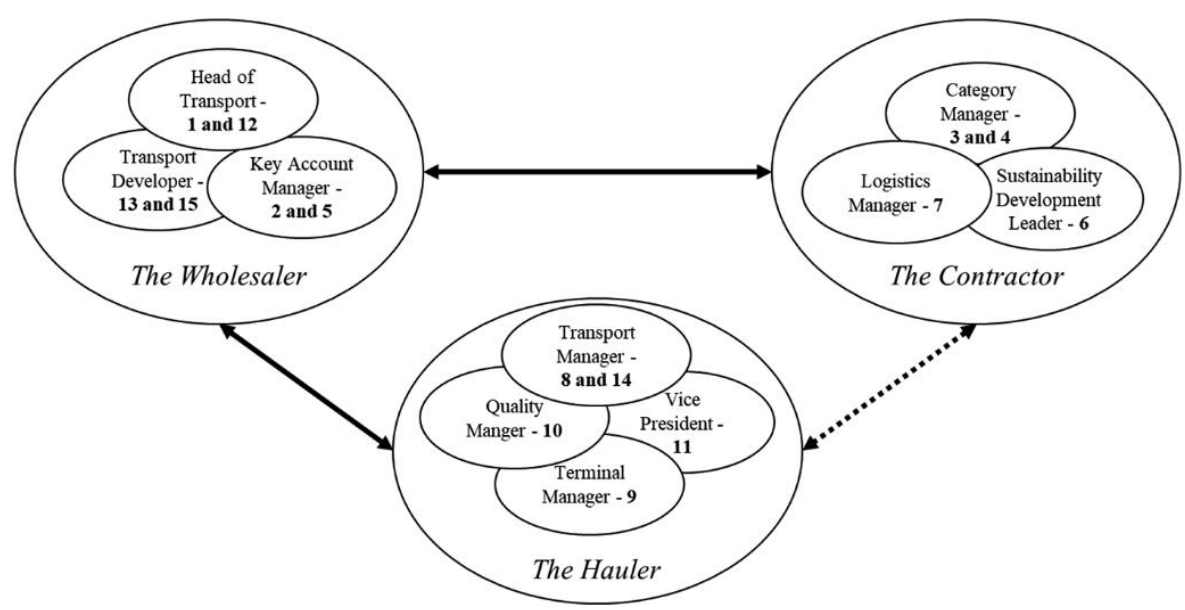

As seen in Table I and Figure 4, several interviews have been conducted during the course of this study. From the first interview with the Head of Transport (1) of the Wholesaler, it became clear that they did not have all the details regarding the relationship between the Wholesaler and Contractor. This led to an interview with one of the Wholesaler's Key Account Managers (2), who had a good understanding of the relationship with the Contractor. The interview with the Key Account Manager was held in conjunction with the Contractor's Category Manager (3) to get a holistic and detailed view of the relationship between the parties.

A second interview was then held with the Category Manager (4) to follow-up on the previous interview and discuss more buyer-specific issues. After that interview, the Wholesaler's Key Account Manager (5) was interviewed once more to capture the development of the relationship with the Contractor. This was followed by two interviews with representatives from the Contractor, the Sustainability Development Leader (6) and Logistics Manager (7), both of whom had in-depth knowledge about specific issues. At this point, a substantial amount of information had been collected from the Contractor and Wholesaler, and some information about the Hauler had been collected from the Wholesaler's perspective. However, to gather more information about the Hauler and its role in the triad, the interviews then turned their focus to managers at the Hauler. The first interview was held with the Transport Manager (8) to get an understanding of the transport situation with regard to new transport solutions and how these would affect the Hauler. To get a more in-depth understanding of the Hauler's terminal operations, the Terminal Manager (9) and Quality Manager (10) were interviewed. Strategic issues and the long-term business relationship with the Wholesaler were then discussed with the Vice President (11).

The managers at the Hauler supplied very detailed information about their operations and how their relationships, especially with the Wholesaler, had developed, but also how they work and communicate with the Contractor. This led to a 
second interview with the Wholesaler's Head of Transport (12) and Transport Developer (13). A second interview with the Transport Manager (14) was held to follow-up on questions that came up in interviews with the Wholesaler as well as with other managers, but this interview also provided a more detailed picture of the situation and the discussion of different transport scenarios. Lastly, an interview was held with the Wholesaler's Transport Developer (15) to acquire information about their environmental goals and strategic work. All interviews, observations and additional secondary data allowed for the case description to gradually evolve.

To evaluate the quality of the research, trustworthiness (Lincoln and Guba, 1985; Halldorsson and Aastrup, 2003), the combined qualities of credibility, transferability, dependability and confirmability were used as a quality criterion. First, credibility was achieved through the study's findings and through matching what the respondents said and the way the researchers interpreted and responded to it. This research project lasted roughly two years, with continuous data collection and meetings with industrial representatives and an extensive amount of time spent in the case setting. Secondly, transferability requires rich descriptive detail of the data so that others can check it elsewhere, or judge the degree of fit (schwandt et al., 2007). This criterion was ensured by interacting with people about the phenomenon and the case in various contexts such as at workshops, conferences, seminars and with peers in various review processes. Thirdly, dependability relates to the logic behind the research process, as well as to how various decisions were made during the process. Keeping records of the entire research process, including the directions and re-directions in the research process (Dubois and Gadde, 2002) - when confronted with new empirical material and input from peers - as well as in the writing of this paper that were taken, ensured the study's dependability. Lastly, confirmability (which is highly intertwined with dependability) means that the findings should be representative of the study and not a result of the researchers' bias. The collected data have to "speak" for themself and the interpretations have to be grounded in the data. We matched the collected data with the main theoretical dispositions outlined in the framework. The arguments made for triads and IMP are consistent with previous literature. The data have been interpreted by several researchers during internal seminars, as well as at international conferences prior to analysis. The data have also been interpreted during the analysis by those who did not partake in the data collection. All in all, the emergent process of confronting theory and the empirical world throughout the entire study contributed its confirmability.

\section{A case illustrating a transport service triad}

In this section, an empirical illustration of a TST is provided together with the description of some initiated and planned changes in the triad, as well as their anticipated effects.

\subsection{The TST involving the Wholesaler, the Contractor} and the Hauler

The triad involves three Swedish firms; the Wholesaler (the supplier of goods and buyer of transport services), Contractor (the buyer of goods) and Hauler (the transport service provider). The Wholesaler is a technical wholesaler supplying installation products to the construction industry, one of its main customers being the construction firm; the Contractor. The Wholesaler has been a main supplier to the Contractor for almost three decades, and during the recent years, the relationship has become closer, with more engagement from both parties to obtain joint benefits.

The Wholesaler handles and ships about 25,000 packages daily (approximately 50 fully loaded trucks) from its central warehouse to one of 35 cross-docking terminals. From the cross-docking terminals, local haulers, such as the Hauler, transport the goods to the construction sites. The Hauler is a small Swedish transport provider acting as a single supplier of transport services to the Wholesaler in the Stockholm area. This relationship has lasted for two decades, and the Hauler has no other customers than the Wholesaler. The Hauler has a fleet of around 50 trucks (branded with the Wholesaler logotype), ranging from small distribution vehicles to large crane trucks. On an average, the whole fleet handles and distributes approximately 1,200 shipments per day to the Wholesaler's customers.

In the next two sections, we describe the efforts to make changes in the triad, some initiated internally in the triad and some by external actors.

\subsection{Changes initiated by actors in the focal TST}

Both the Contractor and many of its sub-contractors use the Wholesaler as a supplier for installation of products. The subcontractors can either make their purchases through the Contractor or through the Wholesaler's e-commerce portal. When the Wholesaler receives orders, each customer gets a specific time-slot for when the goods will be delivered from the Wholesaler by the Hauler. The delivery takes place the day after the order is placed, as this is a built-in function in the Wholesaler's IT system. The service level is more than 99 per cent, and from a general customer perspective, including the Contractor, this is perceived as a "very good" service level. All in all, this means that the Contractor does not need to plan in advance but can place orders within a short time notice.

Because each order and recipient is treated individually, and the sub-contractors' orders are not coordinated with orders from the Contractor, construction sites often get multiple deliveries per day from the Wholesaler through the Hauler. From the Hauler's perspective, this is a challenge because they sometimes get several unrelated time-slots for deliveries the same day to the same construction site. One consequence of the multiple daily deliveries to individual construction sites is that the Hauler sometimes has to spend time waiting at the construction site to arrive exactly in time for their various timeslots. For the Hauler to be efficient, it is important to be able to plan their daily operations without too many time restrictions. Hence, the Hauler regards time-specific deliveries as one of the largest constraints to pursue truck load efficiency. This is especially so when there are very large and complex construction sites involving many deliveries to various subcontractors. In some of these cases, the Hauler does not engage in on-site transport but delivers to the gate and then another hauler takes over the on-site transport and logistics. However, because the Wholesaler is their one and only customer, they 
need to adapt to the Wholesaler's demands on customer service, not least to the Contractor being one of the Wholesaler's main customers.

In one project, involving more than the triad, the Hauler was made responsible for the deliveries of all materials in one category to a large construction site, including deliveries both to the Contractor and to their sub-contractors. In this case, the Hauler had free access to the construction site and could plan their deliveries according to their own logic. This meant that they could load one truck with all materials dedicated for this construction site each day. The Hauler benefitted from this because they only had to drive to the construction site once while still getting paid for each "stop" at the construction site.

Being a transport provider in an urban environment entails planning challenges because of varying congestion conditions and a continuously changing mix of destinations. In general, the Hauler's trucks can get stuck in traffic between 20 and 180 min per day. To handle these issues, the Hauler has started to interact with the Contractor to get one "aggregated" time-slot to each specific construction site every day. From the Contractor's point of view, they prefer that the Wholesaler books the transports directly into the Contractor's internal transport booking system. In this way, the Contractor can keep track of and plan for the various deliveries, e.g. that a distribution truck will arrive tomorrow at 10 a.m. or that the truck arrives weekly on Mondays at 10 a.m. to a specific construction site.

These types of arrangements are site-/project-specific, and thus not possible to agree on for all sites due to that different projects have different logistical arrangements and that different parties are involved. In some cases, as described above, the Hauler has succeeded to arrange for deliveries only once a day to each construction site, in others, not. This has to do with the possibility to interact with key parties in the specific projects. The Hauler's efficiency versus the construction projects' ability to make sufficiently detailed (and continuously adjusted) plans is a key issue in these interactions.

Lately, the Wholesaler has opened up for a dialogue with the Hauler to incorporate the expertise and perspectives of the Hauler to increase the transport efficiency. This would enable the Hauler to bring in their main concerns to achieve efficient resource utilization, including what vehicles to use for different transports, how to combine delivery points in an optimal way, how to avoid the worst congestion, etc. However, the Wholesaler's order and IT system are an obstacle that hinders some of these initiatives, especially the automatic function serving customers on "a day-after" basis. To come to terms with this issue, the Wholesaler has initiated a project together with the Contractor in which they try to reduce the number of deliveries to the Contractor from the Wholesaler from five times (once a day) to twice a week. However, because the subcontractors have not been involved in this initiative, the Hauler still has to deliver several times a day to each construction site.

\subsection{External initiatives affecting the TST}

One example illustrating external initiatives impacting on the

TST regards a Swedish municipality requiring that all goods to a certain large construction site should be delivered through a specific logistics center. As a consequence, the Hauler delivered all products from the Wholesaler to this logistics center and then a dedicated logistics specialist distributed the goods to the various (sub-)contractors at the particular construction site. For the Hauler, this was perceived as positive because they could deliver to one address; the logistics center, instead of to multiple addresses to various (sub-)contractors at the construction site. However, for the Contractor, this meant inefficient use of resources because the Contractor's own terminals and logistics centers could not be used for this project. Instead, they had to pay for using the external, provisionally setup logistics center.

Another example of external initiatives that will impact on the particular TST is that the Swedish Transport Administration, responsible for infrastructure projects in Sweden, has set demands on reducing emissions by 20 per cent when choosing contractors for its projects. How this should be accomplished is not defined in the contracts. To calculate the reduction of emissions, contractors should use a particular calculation tool. The tool enables contractors to calculate the environmental impact on, for instance, material and specific resources, as well as operations. Contractors can receive a premium if they showcase better performance than the required reductions. As the Contractor is a large customer to the Swedish Transport Administration, these demands and economic incentives have become a top priority. Therefore, the Contractor is currently taking the calculation tool into consideration for future projects with the Swedish Transport Administration. Today, the Contractor does not primarily focus on the environmental impact caused by transport, but the main focus is on the materials' environmental impact. However, with increasing demands on climate mitigation, this is expected to change.

\section{Analysis of the transport service triad and its context}

The case analysis is divided into two parts. The first part contains analysis of the focal TST, followed by analysis focusing on the TST's embeddedness in the supply network. Figure 5 illustrates the relationships and connections within the TST, as well as to its network through relationships with "fourth parties".

\subsection{Analysis of the transport service triad}

The first step in this analysis is to categorize the triad and its relationships. The TST in this case is a buyer-initiated triad, i.e. initiated by the Wholesaler as the buyer transport services. In more general terms, the buyer and supplier roles are attributed to different actors depending on whether the exchange of goods or the sourcing of transport services is in focus (Figure 6). However, the TST is defined by the transport service, and therefore, the buyer and supplier of the transport services are the starting point.

The TST can be characterized by the triadic structure, i.e. how the three actors are connected. The connections between the actors of the TST feature a set-of-connected-actors type of triad with two directly connected actors (relation 1 and 2 in Figure 5) and two indirectly connected actors. The triad is, thus, characterized as an open triad where the supplier of transport services, i.e. the Hauler, has no business relationship with the customer of the goods, i.e. the Contractor in this case. 
Figure 5 Relationships and connections in the TST and its surrounding network

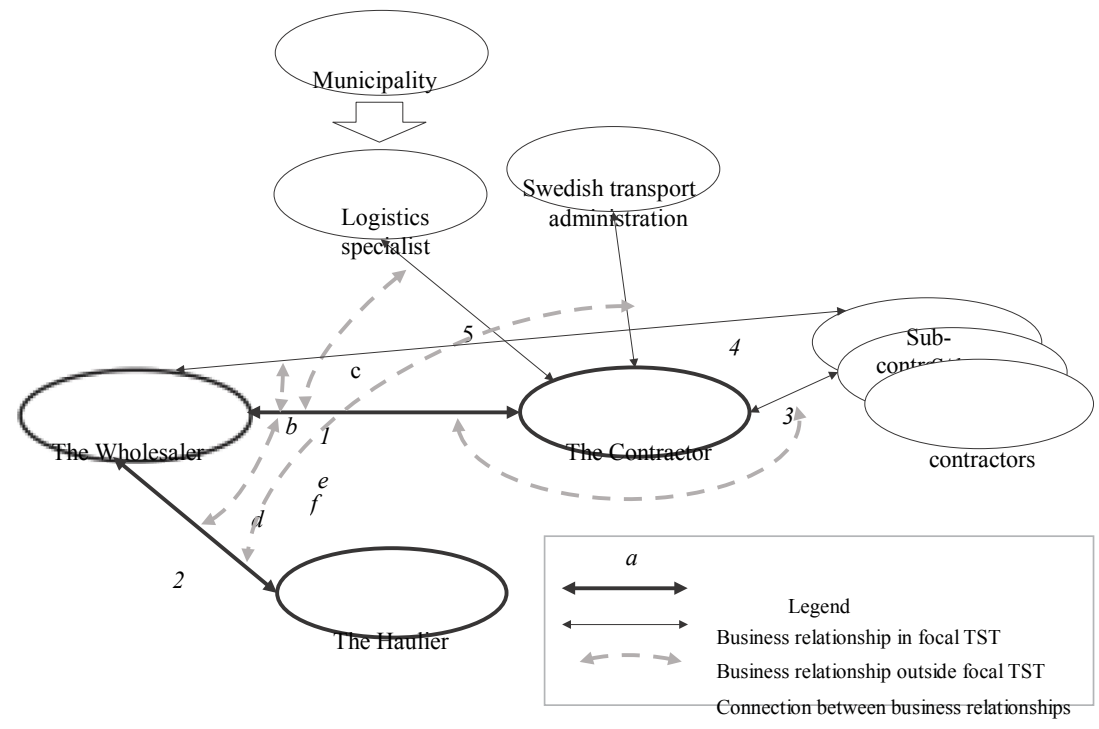

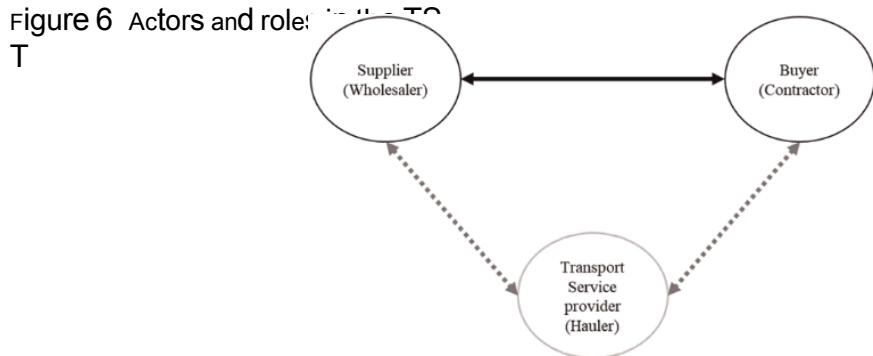

Focus on exchange of goods

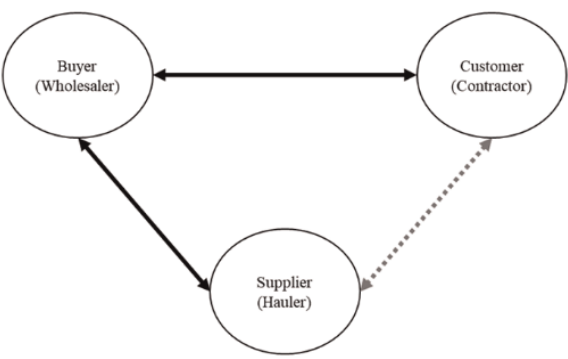

Focus on exchange of transport services
It has been argued that the use of service triads is based on the notion that a supplier (of products) uses a third (service) party to mediate the exchange with its customer. However, in the TST, the transport service provider (i.e. the Hauler) does not take on a mediating role. This role could have been of the character dyadic influence, where the transport provider influences the behavior in the relationship between the two other actors in the triad by providing information to one of the two actors. However, while this is not necessarily the case in TSTs in general, the Hauler took charge of all deliveries to one site in a particular project as a result from dyadic influence by the other two actors in the TST. Transport efficiency could be improved as a result because the number of deliveries could be reduced and the fill-rates of the trucks increased. This solution could have been improved by further adjustments in interaction with the Contractor and its sub-contractors so that the trucks would not have to wait for several hours at site to deliver to all sub-contractors.

Apparently, the Wholesaler's and Hauler's efforts to increase transport efficiency by using the transport resources better has to involve the Contractor because this actor sets the terms for the deliveries to and at site. However, the Contractor's relationships with its sub-contractors are affected because adjustments of the substance, especially the activity links, in these relationships are needed to improve efficiency. Hence, neither dyadic nor triadic interaction was sufficient to further improve the efficiency but would have required interaction with fourth parties. The initiative, however, was taken by the actors in the triad, as the solution developed by them could also be applied in other similar situations in the future, thus investing in development of resource ties and activity links.

The theoretical notion of a meditating role includes normative commitment. For TSTs, it could be argued that the buyer of transport services takes on this role because this actor is involved in business exchange with the two other actors. In the case, the direct relationship between the Wholesaler and Hauler includes normative commitments, while the Hauler's relationship with the Contractor does not. This, in turn, may be a factor hampering the Hauler's ability to influence the possibilities to improve transport efficiency by influencing the Contractor to make adjustments in the relationships with its sub-contractors.

Connectedness among the relationships in the triad in the case, e.g. how the relationship between the buyer and supplier of goods affects the relationship between the buyer and supplier of transport services (see d in Figure 5) affects possible 
adjustments to improve efficiency. The efficiency in terms of transport resource utilization depends on the activity coordination in connection d, i.e. between the two direct relationships within the TST. This connection, in turn, relies on the Wholesaler's IT system, which can be identified as a key resource, in combination with project-specific agreements regarding deliveries, i.e. on the activity coordination at each construction site. In addition, utilization of specific equipment such as a crane trucks requires adjustments in the activity coordination, as it depends on the characteristics of the goods subject to transport, i.e. on the content of project-specific business agreements in 1 , but also on the relationships with other actors in the network in which the triad is embedded.

\subsection{Analysis of the transport service triad as embedded in the supply network}

In the description of efforts made to improve the conditions for efficient use of transport resources, it becomes clear that constraints are set by the activity coordination in the individual construction projects, and that these differ across construction projects owing to other concerns set by the different constellations of actors involved in each project. Despite the fact that the three actors in the TST frequently are involved in similar activities in which the same resources are activated, the connection d between relationships within the TST is projectspecific, and thus depends on conditions external to the triad, which may reduce transport efficiency. This could be illustrated by the project-specific business agreements in 1, are related to the relationships 3 and 4 (where the sub-contractors buy goods from the Wholesaler to be transported by the Hauler) by the connections $a$ and $b$ (see Figure 5). Because the subcontractors' orders are not coordinated with the orders from the Contractor, construction sites often get multiple deliveries each day from the Wholesaler delivered by the Hauler. The transport efficiency suffers as a result. The transport efficiency is further suffering from the inability to coordinate time-slots, resulting in a need for excess transport capacity. This means that deliveries may have to be made at the same time at different addresses. However, if the Hauler could had been given a coordinating, mediating role, this problem may have been reduced. Because this open triad contains no direct link between the Contractor and Hauler (see Figure 5), the mediating role of the service provider cannot be fully utilized.

The TST, as well as the whole supply network of transportrelated actors, is under increasing pressure to reduce emissions. As described in the case, an important buyer of construction projects, the Swedish Transport Administration may improve the conditions for making efficient transport resource utilization a priority which may, in turn, stimulate reduction of certain variations in the activity coordination currently hampering efficient use of the transport resources. Hence, connection e might be utilized to develop routines in connection $\mathrm{d}$ that can be utilized in many, or eventually all, projects in which the focal triad is engaged for the Swedish Transport Administration as a key fourth party. Hence, several TSTs may become connected in developing new ways of linking activities and of tying resources.

The case illustrates how the activity coordination and resource utilization are influenced by individual actors' attempts to utilize their own resources as efficiently as possible.
In focus is the Hauler's efforts to improve the use of its truck fleet. Another example is the Contractor's attempts to utilize its own terminals and how, for some projects, terminals or logistics centers set up by fourth parties, e.g. the municipality, have to be used instead. In the case, the latter concerns connection f, i.e. between relationships 2 and 5 , as well as connection c, i.e. between relationships 1 and 5 . Although the municipality's solution in which it specifies use of a particular logistics center entails favorable conditions for efficient resource utilization from the Hauler's perspective, the Contractor's utilization of its own terminals suffers as a consequence. To capture differences in efficiency in the different setups, the level of analysis has to be expanded to include more than individual TSTs. Also, it points to the need to capture the different actors' perspectives on efficiency.

When connected TSTs are concerned, these are, in our case, limited to those involving the Contractor and Wholesaler because the Hauler works exclusively for the Wholesaler. Both the Wholesaler and Contractor use their terminals and logistics centers as key resources to handle goods shipments and reception across the TSTs in which they are involved. Hence, similarities among the activities, and the possibilities to coordinate activities in proper sequences across TSTs, is paramount for efficient resource utilization in these actors' perspectives.

Also, the IT system used by the Wholesaler is a key resource. As for the features of this resource, however, the standardized delivery routines (i.e. delivering the day after every order), as well as the difficulties to combine deliveries to the same address, are problematic in relation to efficiently utilizing the transport resources. Enabling counterpart-specific adjustments would, in this case, entail improvements in the TST-specific connections between the relationships within individual TSTs while reducing the similarities achieved through standardization across TSTs. Moreover, the number of counterparts impacts on the possibilities to handle such specific adjustments and can thus be seen as an important aspect in analysis of the specific consequences of the connected triads.

While TSTs are generic in their nature, the case illustrates how connections with other relationships and TSTs impact on the possibilities to efficiently utilize resources. However, adjustments of activities to facilitate efficient transport resource utilization are possible to achieve through interaction between all three parties within a specific TST. Long-term collaboration and commitment, including both the TST-specific relationships and connection between them are, therefore, needed to increase the efficiency. Also, long-term relationships with fourth parties, such as the one between the Contractor and Swedish Transport Administration, may contribute to develop sustainable solutions that can be applied on a large scale and also, potentially, in relation to other fourth parties.

\section{Concluding discussion}

In view of an expected increase of more elaborate relationships between buyers and suppliers of transport services (Andersson and Norrman, 2002), the framework suggested in this paper supports analysis of new forms of exchange and networking. Hence, we suggest that the TST is a suitable focal unit of analysis of change in transport systems, and that the suggested 
approach provides a theoretical starting point for systematic study of TSTs as parts of wider supply networks. The latter is of particular importance because other activities and resources have to be adjusted to increase transport efficiency. Three broad issues of managerial relevance and of interest for further studies are addressed below.

First, from a supply network perspective, the issue of how to make better use of transport resources can be expected to become increasingly salient with growing demands on sustainable transport solutions. Until now, the services provided by transport service providers have often been taken for granted and made subject to standardized exchange. Hence, the services have been treated as commodities where direct costs (price) should be minimized (Potter and Lalwani, 2005). These practices do not promote long-term relationships and joint development of, and adjustment to, new solutions. However, external pressure together with improved understanding of the specific conditions that underlie transport service providers' efficiency may result in adjustments in the exchange of goods between buyers and suppliers to better fit with, e.g. the demands of other customers of the transport service providers. If all relevant actors in a TST are involved in the development of the transport services, the possibilities to increase transport efficiency can be greatly enhanced. New requirements and technologies, e.g. electric distribution vehicles requiring charging infrastructures, and thus adjustments to charging in the activity coordination, will also place new demands on adjustments made in interaction among the actors within TSTs.

For each buyer of transport services, the efficiency potentials involved in connected TSTs, as part of the firms' supply network strategies, require recognition. Concentrating the purchases of transport services to a number of suppliers small enough to permit collaboration both with the transport service providers and supply chain counterpart(s) involved in the business exchange of goods is, therefore, of essence. Such collaboration also enables readiness to handle new transport regulations and policies that impact on supply network conditions.

Second, because of the embedded nature of transport services and interdependencies with other activities and resources, transport service providers can only improve their performance if allowed to interact with both the other two actors in TSTs. Such interaction enables the parties to negotiate the right balance between standardized and specific solutions both to enable efficient transport resource utilization (Hertz and Alfredsson, 2003) and at the same time satisfy the needs of all three parties, i.e. considering various efficiency aspects in a broader scope. This highlights the importance to understand the nature and dynamics of the TST.

From the perspective of transport providers, differentiated transport services need to be coordinated across several relationships and TSTs. Opportunities may arise when relationships between buyers and suppliers of goods develop over time, e.g. regarding business content, with various consequences for their requirements on transport services. For transport service providers, these changes may entail opportunities if they are aware of, and alert to, this part of their business context and even more so if they are actively involved in the interaction with the buyers and suppliers of the goods to be transported.

Furthermore, increasing awareness of the business context may inspire transport service providers to develop new business models in terms of new ways of operating and creating value for their customers. The relationship implications of such new business models require analysis of the TSTs because new business content is directly related to the activities performed and the resources activated in the connected relationships of the triads. The suggested framework may contribute to an understanding of the embeddedness of transport services in these complex networks of connected relationships, in contrast with the traditional market analysis that focuses on aggregated levels of business exchange for each type of service, or on dyadic relationships between buyers and suppliers of transport services alone. The triadic approach can become instrumental to understand the development of the transport system because it includes all relevant parties and relationships, as well as the logic framing their actions. However, while arguing that TSTs are generic to transport services, the parties, relationships between them, connections among the relationships and TSTs are unique, and thus need to be identified and analyzed in each specific case.

Third, from the transport policy makers' perspective, microlevel analysis is arguable vital to understand behavioral adjustments to new policies. Transport services is a heterogeneous purchasing category in terms of its relative value and cost which, in turn, depends on how they are embedded in other products and services. Hence, new regulations entail very different consequences in different supply network settings. For many buyers of transport services, however, the transport share of total costs is perceived as marginal, and thus, the incentives to reduce these costs by contributing to more efficient transport resource utilization is limited. Policies resulting in a stronger focus on transport efficiency might, therefore, stimulate more interaction within TSTs. In addition, such efforts might have structuring effects, i.e. result in reducing the number of transport service providers that, in turn, may result in a less fragmented industry structure, and thus better conditions for investments in sustainable transport solutions. The links between micro- and macro-level analyses of transport activity require further attention to improve the understanding of the consequences of different policy measures. For long, the coupling between transport and economic growth has been taken as given in macro-economic models which in itself may have hampered efforts to decouple this relation.

\section{References}

Adobor, H. and McMullen, R.s. (2014), "Strategic purchasing and supplier partnerships - The role of a third party organization", Journal of Purchasing and Supply Management, Vol. 20 No. 4, pp. 1-10.

Anderson, J., Håkansson, H. and Johanson, J. (1994), "Dyadic business relationships within a business network context", Journal of Marketing, October, Vol. 58 No. 4, pp. 1-15.

Andersson, D., Dubois, A., Holma, A.M., and Hulthén, K. (2014), "Triads at the Interface between Supply Networks and Logistics Service Networks", Paper presented at 8th 
Nordic Workshop on Relationship Dynamics (NoRD2014), Oslo (accessed 15-17 October 2014).

Andersson, D. and Norrman, A. (2002), "Procurement of logistics services a minutes work or a multi-year project?", European Journal of Purchasing and Supply Management, Vol. 8 No. 1, pp. 3-14.

Banister, D., Dreborg, K., Hedberg, L., Hunhammar, S., Steen, P. and Åkerman, J. (2000), "Transport policy scenarios for the EU: 2020 images of the future", innovation, Vol. 13 No. 1 , pp. $27-45$.

Bask, A.H. (2001), "Relationships among TPL providers and members of supply chains-a strategic perspective", Journal of Business \& Industrial Marketing, Vol. 16 Nos 6/7, pp. 470-486.

Beier, F.J. (1989), "Transportation contracts and the experience effect: a framework for future research", Journal of Business Logistics, Vol. 10 No. 2, pp. 73-89.

Broekhuis, M. and Scholten, K. (2018), "Purchasing in service triads: the influence of contracting on contract management", International Journal of Operations \& Production Management, Vol. 38 No. 5, pp. 1188-1204.

Burt, R.S. (2000), "The network structure of social Capital", Research in Organizational Behavior, Vol. 22, pp. 345-423.

Carter, J.R. and Ferrin, B.G. (1995), "The impact of transportation costs on supply chain management", Journal of Business Logistics, Vol. 16 No. 1, pp. 189-211.

Choi, T.Y. and Wu, Z. (2009), "Triads", Journal of Supply Chain Management", Vol. 45 No. 1, pp. 8-25.

Dubois, A. (1998), Organising Industrial Activities across Firm Boundaries, Routledge, London.

Dubois, A. and Araujo, L. (2007), "Case research in purchasing and supply management: opportunities and challenges", Journal of Purchasing and Supply Management, Vol. 13 No. 3, pp. 170-181.

Dubois, A. and Fredriksson, P. (2008), "Cooperating and competing in supply networks: making sense of a triadic sourcing strategy", Journal of Purchasing and Supply Management, Vol. 14 No. 3, pp. 170-179.

Dubois, A. and Gadde, L.-E. (2002), "Systematic combining: an abductive approach to case research", Journal of Business Research, Vol. 55 No. 7, pp. 553-560.

Dubois, A., Hulthén, K. and Pedersen, A.-C. (2004), "Supply chains and interdependence: a theoretical analysis", Journal of Purchasing and Supply Management, Vol. 10 No. 1, pp. 3-9.

Easton, G. (2010), "Critical realism in case study research", Industrial Marketing Management, Vol. 39 No. 1, pp. 118-128.

Easton, G., (1995), "Case research as a methodology for industrial networks: a realist apologia", in: Turnbull, P. W., Yorke, D. and Naudé, P. IMP Conference (11th) Interaction, Relationships And Networks: Past - Present Future, pp. 369-391. Manchester, United Kingdom, Manchester Federal School of Business and Management. IMP: 1995 (accessed 7-9 September 1995).

Eisenhardt, K.M. and Graebner, M.E. (2007), "Theory building from cases: opportunities and challenges", Academy of Management Journal, Vol. 50 No. 1, pp. 25-32.

Ellram, L.M. (1996), "The use of the case study method in logistics research", Journal of Business Logistics, Vol. 17, pp. 93-138.
European Commission (2011), "White paper roadmap to single European transport area - Towards a competitive and resource efficient transport system".

European Commission (2016), "Reducing emissions from transport", available at: http://ec.europa.eu/clima/policies/ transport/index_en.htm

Finne, M. and Holmström, J. (2013), "A manufacturer moving upstream: triadic collaboration for service delivery", Supply Chain Management: An International Journal, Vol. 18 No. 1 pp. 21-33.

Flyvbjerg, B. (2006), "Five misunderstandings about casestudy research", Qualitative Inquiry, Vol. 12 No. 2, pp. 219-245.

Gadde, L.-E., Håkansson, H. and Persson, G. (2010), Supply Network Strategies, John Wiley \& Sons, (2nd Ed.).

Gentry, J. (1996), "Carrier involvement in buyer-supplier strategic partnerships", Logistics Information Management, Vol. 9 No. 6, pp. 54-61.

Granovetter, M.s. (1973), "The strength of weak ties", American Journal of Sociology, Vol. 78 No. 6, pp. 1360-1380.

Håkansson, H. and Snehota, I. (1995), Developing Relationships in Business Networks, Routledge, London.

Håkansson, H. and Snehota, I. (2006), "No business is an island: the network concept of business strategy", Scandinavian Journal of Management, Vol. 22 No. 3 , pp. 256-270.

Halinen, A. and Törnroos, J.-Å. (1998), "The role of embeddedness in the evolution of business networks", Scandinavian Journal of Management, Vol. 14 No. 3, pp. 187-205.

Halldorsson, À. and Aastrup, J. (2003), "Quality criteria for qualitative inquiries in logistics", European Journal of Operational Research, Vol. 144 No. 2, pp. 321-332.

Hartmann, E. and Herb, S. (2014), "Opportunism risk in service triads - a social Capital perspective", International Journal of Physical Distribution \& Logistics Management, Vol. 44 No. 3, pp. 242-256.

Havila, V. (1996), "International Business-Relationship Triads, A study of the changing role of the intermediating actor", Doctoral Thesis, Department of Business Studies, Uppsala University.

Hertz, S. and Alfredsson, M. (2003), "Strategic development of third party logistics providers", Industrial Marketing Management, Vol. 32 No. 2, pp. 139-149.

Hertz, S. and Macquet, M. (2006), Creation of Efficiency and Effectiveness by Coordinating Customers' Activities and Strategies of TPL Firms, Turku School of Economics and Business Administration.

Holma, A.-M. (2012), "Interpersonal interaction in business triads-Case studies in corporate travel purchasing", Journal of Purchasing and Supply Management, Vol. 18 No. 2, pp. 101-112.

Holma, A.-M., Bask, A. and Kauppi, K. (2015), "Ensuring corporate travel compliance - Control vs. commitment strategies", Tourism Management, Vol. 51, pp. 60-74.

Holter, A., Grant, D., Ritchie, J. and Shaw, N. (2008), "A framework for purchasing transport services in small and medium size enterprises", International Journal of Physical Distribution \& Logistics Management, Vol. 38 No. 1 , pp. 21-38. 
Isaksson, K. (2012), "Logistics Service Providers going green insights from the Swedish market. Licentiate thesis", Linköping University, Linköping Studies in Science and Technology. Thesis, ISsN 0280-7971.

Johansson, T.B. (2013), Fossilfrihet på Väg, Statens Offentliga Utredningar, Stockholm SOU 2013, p. 84.

Karatzas, A., Johnson, M. and Bastl, M. (2016), "Relationship determinants of performance in service triads: a configurational approach", Journal of Supply Chain Management, Vol. 52 No. 3, pp. 28-47.

Komulainen, H., Mainela, T. and Tähtinen, J. (2016), "Intermediary roles in local mobile advertising: findings from a Finnish study", Journal of Marketing Communications, Vol. 22 No. 2, pp. 115-169.

Krackhardt, D. (1998), "Simmelian ties: Super strong and sticky", in M.R., Kramer and M.A., Neale (Eds) Power and Influence in Organizations, Sage, Thousand Oaks, pp. 21-38.

Laage-Hellman, J. (1989), "Technological Developments in Industrial Networks", Doctoral thesis, Uppsala University, Uppsala.

Lammgård, C. (2007), "Environmental Perspectives on Marketing of Freight Transports - The Intermodal RoadRail Case", Doctoral Thesis, School of Business, Economics and Law, Gothenburg University.

Li, M. and Choi, T.Y. (2009), "Triads in services outsourcing: bridge, bridge decay and bridge transfer", Journal of Supply Chain Management, Vol. 45 No. 3, pp. 27-39.

Lincoln, Y.s. and Guba, E.G. (1985), Naturalistic Inquiry, Sage, Beverly Hills CA.

McKinnon, A., C. and Piecyk, M. (2012), "Setting targets for reducing carbon emissions from logistics: current practice and guiding principles", Carbon Management, Vol. 3 No. 6 , pp. 629-639.

Madhavan, R., Gnyawali, D. and Jinyu, H. (2004), “Two's company, three's a crowd? Triads in cooperative-competitive networks", Academy of Management Journal, Vol. 47 No. 6, pp. 918-927.

Marasco, A. (2008), "Third-party logistics: a literature review", International Journal of Production Economics, Vol. 113 No. 1, pp. 127-147.

Meixel, M.J. and Norbis, M. (2008), "A review of the transportation mode choice and carrier selection literature", The International Journal of Logistics Management, Vol. 19 No. 2, pp. 183-211.

Obstfeld, D. (2005), "Social networks, the tertius iungens orientation, and involvement in innovation", Administrative Science Quarterly, Vol. 50 No. 1, pp. 100-130.

Obstfeld, D., Borgatti, S.P. and Davis, J. (2014), "Brokerage as a process: decoupling third party action from social network structure", In Research in the Sociology of Organizations: Contemporary Perspectives on Organizational Social Networks, (Eds) Daniel J. Brass, Giuseppe Labianca, Mehra Ajay, Daniel S. Halgin and Stephen P. Borgatti, Emerald Publishing Limited, Bingley, West Yorkshire, Vol. 40, pp. 135-159.

Potter, A. and Lalwani, C. (2005), "Supply chain dynamics and transport management: a review", Proceedings of the 10th Logistics Research Network Annual Conference, Cardiff.

Richardson, G.B. (1972), "The organisation of industry", The Economic Journal, September, pp. 883-896.
Ritter, T. (2000), "A framework for analyzing interconnectedness of relationships", Industrial Marketing Management, Vol. 29 No. 4, pp. 317-326.

Ritter, T. and Gemünden, H.G. (2003), "Interorganizational relationships and networks: an overview”, Journal of Business Research, Vol. 56 No. 9, pp. 691-697.

Rodrigues, S., Augusto, V., Naim, M.M. and Potter, A.T. (2010), "Evaluating the causes of uncertainty in logistics operations", International Journal of Logistics Management, Vol. 21 No. 1, pp. 45-64

Rogerson, S. (2016), "Environmental concerns when purchasing freight transport", Doctoral thesis, Chalmers University of Technology, Gothenburg.

Schreiner, A. (2015), "Triadic analysis of business relationship's ending: a case study of a dyad and a third actor", Journal of Business \& Industrial Marketing, Vol. 30 No. 8, pp. 891-905.

Schwandt, T.A., Lincoln, Y.S. and Guba, E.G. (2007), "Judging interpretations: but is it rigorous? Trustworthiness and authenticity in naturalistic evaluation", New Directions for Evaluation, Vol. 2007 No. 114, pp. 11-25.

Selviaridis, K. and Spring, M. (2007), "Third party logistics: a literature review and research agenda", The International Journal of Logistics Management, Vol. 18 No. 1, pp. 125-150.

Sengupta, S., Niranjan, T. and Krishnamoorthy, M. (2018b), "Trends and directions in service triads research", International Journal of Physical Distribution \& Logistics Management, Vol. 48 No. 3, pp. 333-360.

Sengupta, S., Niranjan, T., Krishnamoorthy, M. and Van der Valk, W. (2018a), "A client-centric risk-based taxonomy of service triads", The Service Industries Journal, pp. 1-23, (accessed Aug, 2018).

Siltaloppi, J. and Vargo, S.L. (2017), "Triads: a review and analytical framework", Marketing Theory, Vol. 17 No. 4, pp. 395-414.

Simmel, G. (1908), Sociology: Inquiries into the Construction of Social Forms, Vol. 2, (Ed.) and trans. by Anthony J. Blasi, Anton K. Jacobs and Matthew Kanjiranthinkal (2009); intro. Horst J. Helle, Brill, Leiden and Boston.

Simmel, G. (1950), The Sociology of Georg Simmel, Free Press, New York, NY.

Smith, P.C. and Laage-Hellman, J. (1992), "Small group analysis in industrial networks", in Axelsson, B. and Easton G. (Eds), (1992) Industrial Networks: A New View of Reality, Routledge, London.

Swedish Government (2017), available at: www.regeringen. se/artiklar/2016/06/miljomalsberedningen-foreslar-nyautslappsmal-och-en-klimatstrategi/

Tanskanen, K., Holmström, J. and Öhman, M. (2015), "Generative mechanisms of the adoption of logistics innovation: the case of on-site shops in construction supply chains", Journal of Business Logistics, Vol. 36 No. 2, pp. 139-159.

Van der Valk, W. and van Iwaarden, J. (2011), "Monitoring in service triads consisting of buyers, subcontractors and end customers", Journal of Purchasing and Supply Management, Vol. 17 No. 3, pp. 198-206.

Van Iwaarden, J. and van der Valk, W. (2013), "Controlling outsourced service delivery: managing service quality in 
business service triads", Total Quality Management \& Business Excellence, Vol. 24 Nos 9/10, pp. 1046-1061.

Vedel, M. (2016), "The triad value function - theorizing the value potential of connected relationships", Journal of Business \& Industrial Marketing, Vol. 31 No. 7, pp. 849-860.

Vedel, M., Holma, A.-M. and Havila, V. (2016), "Conceptualizing inter-organizational triads", Industrial Marketing Management, Vol. 5, pp. 139-147.

Wynstra, F., Spring, M. and Schoenherr, T. (2015), "Service triads: a research agenda for buyer-supplier-customer triads in business services", Journal of Operations Management, Vol. 35, pp. 1-20.

Yamagishi, T., Gillmore, M.R. and Cook, K.S. (1988), "Network connections and the distribution of power in exchange networks", American Journal of Sociology, Vol. 93 No. 4, pp. 833-851.

Corresponding author

Kajsa Hulthen can be contacted at: kajsa.hulthen@ chalmers.se

For instructions on how to order reprints of this article, please visit our website: www.emeraldgrouppublishing.com/licensing/reprints.htm

Or contact us for further details: permissions@emeraldinsight.com 